\title{
Temporal-spatial Disparity and Dynamic Distribution Evolution of the Upgrading of Manufacturing Industry in China
}

\author{
Fanchao Kong \\ School of Statistics \\ Shandong University of Finance and Economics \\ Ji'nan, China
}

\begin{abstract}
Under the background of the double pressure abroad and the profound changes of domestic factor structure, as the core elements of the industrialization process, the upgrading of the manufacturing industry dominates the process of transformation and upgrading of China's overall industrial structure to a large extent. Based on Dagum gini coefficient, we study the temporal-spatial disparity and the distribution evolution of the Upgrading of Manufacturing Industry in china from 1999 to 2014. The results show that: The overall disparity present a decreasing trend of the Upgrading of Manufacturing Industry in china. East and west region perform "inverse u-shaped" type development trend, and fluctuation trend in middle. Intensity of transvariation is the dominant factor of spatial disparity and the gap within the region is a secondary factor. It is conducive to narrow regional disparity of manufacturing upgrading and achieve industrial restructuring and upgrading objectives.
\end{abstract}

Keywords-Upgrading of Manufacturing Industry; Dagum gini coefficient

\section{INTRODUCTION}

With the rise of global emerging industrial revolution, countries have realized that remodeling manufacturing has become the key to leading the global economic development in the post-industrial era. Major countries have begun to put forward the strategy that promotes the development of advanced manufacturing industry. From the "Industrial 4.0" strategy implemented in Germany to the "New Industrial France" program in France, to the "Manufacturing Promotion Act", "revitalizing the US manufacturing policy framework", "National Strategic Plan for Advanced Manufacturing" in the United States, the new round of global manufacturing industry is re-layout. In May 2015, China issued "China Manufacturing 2025" to implement the strategic objectives of the upgrading of manufacturing, aimed at promoting China's manufacturing industry structure into a high level.

For a long time, with cheap labor costs, low-end processing, china's manufacturing industry is developing rapidly, especially labor-intensive industries, Most of our manufacturing industry is located at the bottom of the "smile curve" and at the lower end of the manufacturing value chain. As China's demographic dividend subsided, rising labor costs, overcapacity problems, most manufacturing companies are difficult to sustain, and the risk of "low-end lock" and "path dependence" of manufacturing industry increased. China's manufacturing industry needs to put forward the manufacturing development strategy of promoting manufacturing upgrade to adapt to changes in the market. The spatial distribution of the manufacturing industry has become an important factor restricting the regional economic development.

\section{LITERATURE REVIEW}

In the literature related to the upgrading of manufacturing, the existing literature mainly analyzes the manufacturing upgrading mechanism from different aspects including Global Value Chain (Gereffi,1999), Foreign Direct Investment (Ahmed, 2012), Producer Services (Sheng, 2014) and Foreign Direct Investment (Gia and Shen, 2016). These studies provide a large number of theoretical basis for the upgrading of manufacturing, but most of the research focuses on the static analysis of the industrial level, lacking of dynamic analysis of regional manufacturing upgrade. Under the influence of industry differentiation, development stage, regional attribute and foreign development environment, the manufacturing upgrade shows unbalanced regional development characteristics.

The literatures show that the development of manufacturing industry in China has the characteristics of spatial agglomeration (Luo and Cao, 2005; Liu et al., 2011; Wen and Xian, 2014). The types of spatial concentration trend in manufacturing have significant differences. Capitalintensive industries and technology-intensive industries have a relatively high level of spatial agglomeration. laborintensive industries tend to gather in the eastern coastal areas. Whether this spatial agglomeration or regional transfer feature facilitates the process of manufacturing upgrades and narrows the spatial gap between regional manufacturing upgrades? Further, what is the pattern of evolution of China's manufacturing industry? How is its dynamic transition path? Few scholars have systematically studied the temporal and spatial evolution of China's manufacturing industry from a dynamic perspective. In this paper, in order to reveal the temporal and spatial evolution characteristics and laws of 
manufacturing industry, we measured the spatial gap and its evolution trend of China's manufacturing industry with Dagum Gini coefficient.

\section{VARIABLE, MethodOlOGY AND DATA}

\section{A. Methodology and Data}

In order to solve the problem of spatial gap, Dagum proposed a new Gini coefficient and its decomposition method. The Dagum Gini coefficient is defined as (1):

$$
G=\frac{\sum_{j=1}^{k} \sum_{h=1}^{k} \sum_{i=1}^{n_{j}} \sum_{r=1}^{n_{h}}\left|y_{j i}-y_{h r}\right|}{2 n^{2} \bar{y}}
$$

$k$ represents the number of regions, $n$ represents the sum of the number of provinces and cities in each region, $y$ represents the average level of China's manufacturing upgrade. Dagum Gini coefficient can be decomposed into three parts: regional contribution $\left(G_{w}\right)$, interregional difference contribution $\left(G_{n b}\right)$ and intensity of transvariation $\left(G_{t}\right)$. The corresponding formula can be expressed as follows:

$$
\begin{aligned}
G= & G_{w}+G_{n b}+G_{t} \\
G_{j j}= & \frac{\sum_{i=1}^{n_{j}} \sum_{r=1}^{n_{j}}\left|y_{j i}-y_{j r}\right|}{2 n_{j}{ }^{2} \bar{y}_{j}} \\
G_{w}= & \sum_{j=1}^{k} G_{j j} p_{j} s_{j} \\
G_{j h}= & \frac{\sum_{i=1}^{n_{j}} \sum_{r=1}^{n_{h}}\left|y_{j i}-y_{h r}\right|}{n_{j} n_{h}\left(\bar{y}_{j}+\bar{y}_{h}\right)} \\
G_{n b}= & \sum_{j=2 h=1}^{k} \sum_{j h}^{j-1} G_{j h}\left(p_{j} s_{h}+p_{h} s_{j}\right) D_{j h} \\
G_{t}= & \sum_{j=2 h=1}^{k} \sum_{j h}^{j-1} G_{j h}\left(p_{j} s_{h}+p_{h} s_{j}\right)\left(1-D_{j h}\right) \\
D_{j h}= & \frac{d_{j h}-p_{j h}}{d_{j h}+p_{j h}} \\
d_{j h} & =\int_{0}^{\infty} d F_{j}(y) \int_{0}^{y}(y-x) d F_{h}(x) \\
p_{j h} & =\int_{0}^{\infty} d F_{h}(y) \int_{0}^{y}(y-x) d F_{j}(x)
\end{aligned}
$$

This paper takes 30 regions of China (excluding Tibet, Hong Kong, Macao and Taiwan) as samples. The sample time span was 1999-2014. The data of 21 manufacturing segments in this paper are from the China Industrial Statistics Yearbook.

\section{B. Variable}

Liu et al. (2008) argue that the change in the interindustry share is not the essence of the evolution of the industrial structure, and only the industrial labor productivity has been improved, the evolution of industrial structure is meaningful.

In order to reflect the change of the proportion of the subsectors within the manufacturing industry and the level of labor productivity, this paper uses the index method to construct the manufacturing industry upgrade level index in the form of (11):

$$
y_{i t}=\sum_{n=1}^{N} r_{\text {int }} L_{\text {int }}
$$

$r_{\text {int }}$ represents the proportion of the output value of the $\mathrm{n}$-th manufacturing segment in $i$ province, $L_{\text {int }}$ represents the corresponding Labor productivity. $\mathrm{N}$ is the total number of manufacturing sector segments $(\mathrm{N}=21)$. The share of department with high labor productivity increases, the greater the index.

\section{EMPIRICAL RESULTS}

In this paper, we divided the 30 provinces and cities in China into eastern, central and western region, and measured the overall gap and its disparity of China's manufacturing upgrading from 1999 to 2014 with the Dagum Gini coefficient and its decomposition formula. The results are shown in "Table I" and "Table II".

\section{A. The Overall Spatial Disparity of China 's Manufacturing Upgrading}

TABLE I. RESUlTS OF SPATIAL DisParity

\begin{tabular}{|c|c|c|c|c|c|c|c|}
\hline \multirow{2}{*}{ year } & \multirow{2}{*}{$G$} & \multirow{2}{*}{$G_{w}$} & \multirow{2}{*}{$G_{n b}$} & $G_{t}$ & \multicolumn{3}{|c|}{ Contribution rate } \\
\cline { 6 - 8 } & & & & & $G_{w}$ & $G_{n b}$ & $G_{t}$ \\
\hline 1999 & 0.273 & 0.078 & 0.048 & 0.148 & 0.284 & 0.175 & 0.541 \\
\hline 2000 & 0.282 & 0.087 & 0.037 & 0.159 & 0.307 & 0.131 & 0.562 \\
\hline 2001 & 0.286 & 0.088 & 0.055 & 0.144 & 0.307 & 0.191 & 0.502 \\
\hline 2002 & 0.268 & 0.079 & 0.056 & 0.133 & 0.295 & 0.209 & 0.496 \\
\hline 2003 & 0.249 & 0.072 & 0.027 & 0.151 & 0.287 & 0.107 & 0.605 \\
\hline 2004 & 0.227 & 0.069 & 0.025 & 0.133 & 0.303 & 0.112 & 0.586 \\
\hline 2005 & 0.225 & 0.069 & 0.025 & 0.131 & 0.307 & 0.112 & 0.581 \\
\hline 2006 & 0.200 & 0.062 & 0.031 & 0.107 & 0.310 & 0.155 & 0.535 \\
\hline 2007 & 0.185 & 0.057 & 0.048 & 0.080 & 0.306 & 0.262 & 0.433 \\
\hline 2008 & 0.184 & 0.056 & 0.043 & 0.084 & 0.306 & 0.236 & 0.458 \\
\hline 2009 & 0.183 & 0.056 & 0.048 & 0.078 & 0.308 & 0.263 & 0.430 \\
\hline 2010 & 0.173 & 0.051 & 0.054 & 0.068 & 0.294 & 0.313 & 0.393 \\
\hline 2011 & 0.171 & 0.050 & 0.050 & 0.071 & 0.294 & 0.292 & 0.414 \\
\hline 2012 & 0.163 & 0.047 & 0.047 & 0.069 & 0.289 & 0.291 & 0.420 \\
\hline 2013 & 0.138 & 0.043 & 0.022 & 0.074 & 0.310 & 0.158 & 0.532 \\
\hline 2014 & 0.128 & 0.038 & 0.030 & 0.059 & 0.299 & 0.236 & 0.465 \\
\hline
\end{tabular}

In "Table I", during the period of the 1999-2014 sample survey, the overall Dagum Gini coefficient of China's manufacturing upgrade present a decreasing trend. The overall spatial gap rose from 0.273 in 1999 to 0.286 in 2001 and then fell to 0.128 in 2014. Based on 1999 and 2002, the spatial disparities decreased by $4.95 \%$ and $6 \%$ respectively in 2014. During the period from 1999 to 2001, the Dagum 
Gini coefficient increased from 0.273 to 0.286 , and the overall spatial gap increased by $2.42 \%$. During this period, the spatial gap of manufacturing upgrading increased year by year. During the period from 2002 to 2014, the Dagum Gini coefficient decreased from 0.268 to 0.128 , indicating that the spatial gap of China's manufacturing industry since 2002 has steadily declined year by year.

\section{B. The Evolution Trend of Spatial Gap in the Region}

TABLE II. RESULTS OF INTERREGIONALSPATIAL DISPARITY

\begin{tabular}{|c|c|l|c|c|c|c|}
\hline \multirow{2}{*}{ year } & \multicolumn{3}{|c|}{ Region Gini Coefficient } & \multicolumn{2}{c|}{ Interregional Gini Coefficient } \\
\cline { 2 - 7 } & east & central & west & $\begin{array}{c}\text { east }- \\
\text { central }\end{array}$ & $\begin{array}{c}\text { east }- \\
\text { west }\end{array}$ & $\begin{array}{c}\text { central }- \\
\text { west }\end{array}$ \\
\hline 1999 & 0.237 & 0.107 & 0.280 & 0.298 & 0.343 & 0.230 \\
\hline 2000 & 0.258 & 0.190 & 0.281 & 0.301 & 0.323 & 0.261 \\
\hline 2001 & 0.263 & 0.167 & 0.302 & 0.295 & 0.327 & 0.278 \\
\hline 2002 & 0.225 & 0.142 & 0.305 & 0.266 & 0.324 & 0.268 \\
\hline 2003 & 0.225 & 0.134 & 0.223 & 0.268 & 0.321 & 0.200 \\
\hline 2004 & 0.209 & 0.107 & 0.257 & 0.219 & 0.278 & 0.221 \\
\hline 2005 & 0.221 & 0.087 & 0.256 & 0.217 & 0.280 & 0.206 \\
\hline 2006 & 0.188 & 0.080 & 0.251 & 0.185 & 0.245 & 0.195 \\
\hline 2007 & 0.186 & 0.067 & 0.203 & 0.184 & 0.228 & 0.170 \\
\hline 2008 & 0.186 & 0.050 & 0.212 & 0.178 & 0.228 & 0.170 \\
\hline 2009 & 0.180 & 0.093 & 0.185 & 0.185 & 0.221 & 0.164 \\
\hline 2010 & 0.156 & 0.083 & 0.184 & 0.173 & 0.221 & 0.156 \\
\hline 2011 & 0.153 & 0.086 & 0.185 & 0.174 & 0.218 & 0.154 \\
\hline 2012 & 0.142 & 0.094 & 0.161 & 0.177 & 0.201 & 0.142 \\
\hline 2013 & 0.130 & 0.102 & 0.134 & 0.140 & 0.162 & 0.129 \\
\hline 2014 & 0.124 & 0.096 & 0.093 & 0.145 & 0.151 & 0.103 \\
\hline
\end{tabular}

In "Table II", East and west region perform "inverse ushaped" type development trend, and fluctuation trend in middle. For the eastern, based on 1999, the spatial gap of the average annual declined by $4.22 \%$ in 2014.The maximum Gini coefficient in the eastern region is 0.263 in 2001, the lowest is 0.124 in 2014, and its value presents downward trend in the period from 2001 to 2014, indicating that the gap between the provinces in the eastern region is gradually narrowing. For the central, if the base period is 1999, the spatial gap of manufacturing upgrade level of the average annual decreased by $0.72 \%$ in 2014. The decline was significantly lower than the eastern. The maximum value of its internal Gini coefficient is 0.19 in 2000 and the minimum value is 0.05 in 2008, showing a significant trend of repeated fluctuation. For the western, if the base period is 1999, the spatial disparity decreases by $7.1 \%$ annually, and its descending rate is obviously larger than that of the eastern and central. The Dagum Gini coefficient of the internal space rises first and then decreases steadily, and reaches the maximum value of 0.305 in 2002 , Down to a minimum of 0.093 in 2014. This may be related to the implementation of a series of national strategies such as the development of the western region. The policy makes the development of the manufacturing structure in the western region converge and its internal gap is further narrowed.

In addition, the gap between the regional upgrading of manufacturing industry in China shows a decreasing trend during the investigation period, which shows that the gap between the east-central, central- west and the east-west are gradually narrowed with the passage of time. Intensity of transvariation is the dominant factor of spatial disparity and the gap within the region is a secondary factor.

\section{CONCLUSION}

Although the overall spatial gap of China's manufacturing upgrade is shrinking, its imbalances still exist. In order to narrow the spatial gap, based on the development characteristics of regional manufacturing industry, it is necessary to co-ordinate regional development strategy and industrial planning, optimize the industrial layout and enhance the leading role of the industry.

\section{REFERENCES}

[1] G. Gereffi. "International trade and industrial upgrading in the apparel commodity chain,” Journal of International Economic, vol.1, pp. 37-70, 1999.

[2] Y, Luo and L.L. Cao. "A Positive Research on Fluctuation Trend of China's Manufacturing Industrial Agglomeration Degree, " Eoconomic Research Journal,vol.8,pp. 106-127, 2005.

[3] F, Sheng. "The Spatial Agglomeration of Producer Service Industry and the Upgrading of Manufacturing Industry: Mechanism and Experience," Industrial Economics Research,vol.2, pp. 32-39, 2014.

[4] H.G. Liu, W.D. Liu and A.G. Liu "The Quantitative Study on InterRegional Industry Transfer," China Industrial Economics,vol.6,pp. 79-88, 2011. 